\title{
HCV/HTLV Coinfection: Does HTLV-1 Interfere in the Natural History of HCV-Related Diseases?
}

\author{
Marcelo Costa Silva, ${ }^{1 *}$ Carolina Alves Costa Silva, ${ }^{1}$ Gustavo Uzêda Machado, ${ }^{1}$ Ajax Atta, ${ }^{2}$ \\ Songeli M. Freire, ${ }^{\mathbf{3}}$ Edgar Carvalho, ${ }^{4}$ Maria Isabel Schinoni, ${ }^{5}$ and Raymundo Paraná ${ }^{\mathbf{5}}$ \\ ${ }^{1}$ Department of Hepatology, Federal University of Bahia, Bahia, Brazil \\ ${ }^{2}$ Clinical and Toxicological Analysis, Federal University of Bahia, Bahia, Brazil \\ ${ }^{3}$ Immunology Laboratory of the Health Science Institute, Federal University of Bahia - Scholar \\ CNPq / INCT-DT/MCT/CNPq, Bahia, Brazil \\ ${ }^{4}$ Immunology Service of the University Hospital Professor Edgar Santos, Federal University of Bahia, Bahia, \\ Brazil \\ ${ }^{5}$ Hepatology Center of the University Hospital Professor Edgar Santos, Federal University of Bahia, Bahia, Brazil
}

Hepatitis $\mathrm{C}$ virus (HCV) and human T-lymphotropic virus type 1 (HTLV-1) coinfection occurs in many regions. However, few studies have focused on the natural history of HCVinduced liver disease in coinfected patients. To describe the clinical, epidemiological, and histopathological aspects of HTLV-1/HCV coinfection in Brazil. A cross-sectional study with 23 patients coinfected with HCV/HTLV. The control groups consisted of 21 patients monoinfected with $\mathrm{HCV}$ and 20 patients monoinfected with HTLV-1. The cytokine profiles (Th1 and Th2 cell responses), clinical, laboratory features, and histopathological aspects were examined. The control group for cytokine analysis validation consisted of patients monoinfected with HTLV, and a fourth group consisted of healthy blood donors. No anthropometric differences present between the three infected groups. We observed higher serum concentrations of IFN- $\gamma$ in patients coinfected with HCV/HTLV-1 than those in $\mathrm{HCV}$ monoinfected patients. The HCV/ HTLV-1 coinfected group also exhibited a higher degree of liver steatosis than the HCV monoinfected patients. Results suggest that HCV/HTLV-1 coinfection may result in a different pattern of HCV infection due to the immunologic disorders likely associated with HTLV-1, but there is no clear evidence of the HTLV role in the natural history of HCV infection. J. Med. Virol. 88:1967-1972, 2016. (C) 2016 Wiley Periodicals, Inc.

KEY WORDS: cytokines; epidemiology; hepatitis C virus; T-lymphotropic virus type $1 ; \mathrm{HCV}$

\section{INTRODUCTION}

Chronic hepatitis C virus (HCV) infection affects more than 170 million people worldwide [Poynard et al., 2003]. Approximately, 20\% of HCV carriers develop cirrhosis, and of these, 3-8\% progress to hepatocellular carcinoma (HCC) [Seeff, 1997]. Several host-related risk factors are associated with more severe disease progression, such as gender, metabolic syndrome, age, and race. In addition, virological variables are also related to the severity of liver disease, including the HCV genotype and viral load [Poynard et al., 1997].

In addition, coinfection has also emerged as an important factor in morbidity related to severe progression of liver fibrosis. The deleterious effects of human immunodeficiency virus (HIV) and hepatitis B virus (HBV) on fibrosis progression have been well documented [Sulkowski et al., 2000]. In contrast, the impact of HCV and human T-lymphotropic virus type 1 (HTLV-1) coinfection on the natural history of HCV is largely unknown. HCV/HTLV-1 coinfection has been described in some geographic areas, likely due to overlapping mechanisms of transmission. Because HTLV-1 causes immunological disorders in humans, it is postulated that HCV/HTLV-1 coinfection may increase the rate of disease progression and produce

Grant sponsor: CNPq (Universal); Grant sponsor: LIA Project; Grant sponsor: Universal Edit Project

Conflict of interest: The authors have no conflicts of interest related to this paper.

${ }^{*}$ Correspondence to: Marcelo Costa Silva, Anchieta Street, no. 60, Bairro Centro Ipiaú, Bahia CEP: 45570-000, Brasil.

E-mail: drmarcelocsilva@globo.com

Accepted 18 March 2016

DOI 10.1002/jmv.24538

Published online 22 April 2016 in Wiley Online Library

(wileyonlinelibrary.com). 
an increased risk of $\mathrm{HCC}$ and a poorer response to antiviral therapy [Tachibana et al., 1988; Stuver et al., 1996; Kishihara et al., 2001].

HTLV-1 is implicated in immunoproliferative disorders, such as adult T-cell leukemia/lymphoma; nevertheless, no studies have reported the relationship between liver fibrosis progression and hepatic carcinogenesis in patients coinfected with HCV and HTLV-I [Takatsuki et al., 1977; Poiesz et al., 1980].

African-Brazilians comprise more than $80 \%$ of the population of Salvador, the capital city of the state of Bahia. As expected, a high prevalence of HTLV-1 infection has been reported in this area. In addition, the HCV prevalence is $1.5 \%$ of the population [Okuda, 1992; Bittencourt, 2006]. Therefore, this region provides a unique opportunity to study the interaction between HTLV-1 and HCV infection, which is the main objective of this study.

\section{MATERIALS AND METHODS}

From March 2009 to December 2013, a crosssectional study was performed on 44 patients selected from a referral center for liver disease of the Federal University Hospital of Bahia. This sample included 23 patients who were coinfected with HCV and HTLV-1 (group 1) and 21 patients who were infected with HCV alone (group 2). These two groups were matched by age $( \pm 5$ years) and gender. To obtain control subjects for the validation of the serum cytokine tests, we also selected 20 patients infected with HTLV-I alone who did not manifest the disease (group 3). In addition, we included a fourth group composed of healthy volunteer blood donors to validate the immunological tests (group 4).

The subjects in group 3 were selected from the database of the Immunopathology Department at the Pharmacy School of the Federal University of Bahia, and the subjects in group 4 were selected from the database of the Hospital Blood Transfusion Center.

The assessment consisted of a clinical and epidemiological questionnaire as well as clinical and laboratory analyses (biochemical liver tests and autoantibody and cytokine assay profiles).

For patients who had previously undergone a liver biopsy, a histopathological review was performed by a single experienced liver pathologist who was not aware of the serologic status of the patient.

The immunologic profile included the serum concentrations of Type-1 T helper (Th1) cell cytokines (interferon [IFN]- $\gamma$ and interleukin [IL]-2) for all of the $44 \mathrm{HCV}$ patients participating in the study (groups 1 and 2). The Human Basic Kit, Flow CytomoxBMS8420FF (Bioscience and Bender Medsystems, Wien, Austria), was used. For external validation, the cytokine results were compared with the results of groups 3 and 4 .

The Type-2 T helper (Th2) cell profile (IL-4, IL-5, and IL-6) was assessed in 10 patients from group 1 , and eight patients from group 2 who were randomly selected. To evaluate the cytokine levels, we used the Human Basic Kit, Flow Cytomox-BMS8420FF (Bioscience, Miami, FL).

The autoimmunity profiles of groups 1 and 2 were investigated by determining the levels of antinuclear antibodies (ANA), anti-smooth muscle antibodies (ASMA), anti-mitochondrial antibodies (AMA), anti-TPO antibodies, anti-neutrophil cytoplasmic antibodies (ANCA), rheumatoid factor, cryoglobulins, antiSSA antibodies, anti-SSB antibodies, haptoglobin, anti-liver/kidney microsome antibodies (anti-LKM-I), anti-beta-2-glycoprotein antibodies (A, G, M), anticardiolipin IgG antibodies, IgA, and IgM (Orgentec, Mainz, Germany).

The presence of cryoglobulinemia was determined by the cryoprecipitation of samples in tubes for seven days at $4^{\circ} \mathrm{C}$. The cryoprecipitates obtained were dissolved via incubation at $37^{\circ} \mathrm{C}$ for $30 \mathrm{~min}$ to detect the presence of cryoglobulins. Indirect immunofluorescence of HEp-2 cells was performed to investigate anti-nuclear antibodies. Anti-smooth-muscle, anti-mitochondrial, and anti-LKM1 antibodies were investigated by indirect immunofluorescence using histological sections of rat kidney, liver, and stomach.

The IgA, IgG, and IgM isotypes of anti-beta-2glycoprotein I and anti-cardiolipin were measured by indirect ELISAs using commercial kits (Orgentec). The aminotransferase levels were determined in an automated dry-chemistry biochemical analyzer (Johnson and Johnson, Brunswick, NJ), and the ferritin levels were determined with a chemiluminescence immunoassay (Access two, Beckman-Coulter, VI).

The HCV viral loads in the group of patients coinfected with HCV and HTLV-1 and in the group of patients infected with HCV alone were evaluated using the COBAS TaqMan ${ }^{\mathbb{B}}$ HCV Quantitative Test. The results are expressed as IU/ml.

\section{Statistical Analysis}

The data were processed with Version 16.0 of the Statistical Package for the Social Sciences program (SPSS Inc., Chicago, IL, Release 16.0.2, 2008). Categorical variables are presented as absolute and relative frequencies; continuous variables are presented as measures of central tendency and dispersion (mean \pm standard deviation). The normality of the distribution was assessed with the KolmogorovSmirnov test (K-S test). Continuous variables were compared using a $t$-test for independent samples. The relationship between categorical variables was determined by Pearson's chi-squared test $\left(\chi^{2}\right)$ and/or Fisher's exact test. The analyses were bilateral (two-tailed), and a value of $P \leq 0.05$ was considered statistically significant. The program Prism ${ }^{\mathrm{B}}$ Version 5.03 (GraphPad) was used for the analysis of cytokines. Pearson's and d'Agostino's tests were used to analyze continuous variables. The means and medians were evaluated with Student's unpaired 
$t$-test and the Mann-Whitney nonparametric test, respectively. The medians from three or more groups were compared with the Kruskal-Wallis test, and correlation analysis was performed with Spearman's test.

\section{RESULTS}

The anthropometric assessment of patients showed that groups 1 (HCV/HTLV coinfected patients) and 2 (HCV monoinfected patients) had similar characteristics. The average ages of patients in groups 1 and 2 were $48.1 \pm 6.0$ and $49.3 \pm 9.7$ years (Table I), respectively.

Regarding the risk factors for parenterally transmitted viruses, patients in group 1 were more likely to have been intravenous drug users (IVDU) and/or have used inhaled illegal drugs than patients in group $2(34.8 \%$ vs. $14.3 \%)$. In contrast, patients in group 2 reported a higher frequency of having used intravenous vitamin complexes and non-disposable glass syringes ( $85 \%$ vs. $77.3 \%$ ). However, this variable was not statistically significant (Table II).

Concerning the symptoms, among the patients in group 1, $43.5 \%$ reported fatigue vs. $27.8 \%$ in group 2 $(P=0.35)$. Arthralgia was reported by $43.5 \%$ of the patients in group 1 and by $33 \%$ of patients in group 2
$(P=0.54)$. The laboratory analysis showed higher mean transaminase levels in group 1 . The AST level was $71.0 \pm 63.0 \mathrm{IU}$ in group 1 versus $62.6 \pm 41.7 \mathrm{IU}$ in group $2(P=0.64)$.

The mean ALT level in group 1 was $67.5 \pm 92.2 \mathrm{IU}$ versus $64.6 \pm 58.8 \mathrm{IU}$ in group 2 , but the difference was not statistically significant. All of the other laboratory parameters assessed were similar for both groups. The only difference was found in the assessment of total proteins; the average level of globulins in group one was $3.6 \pm 0.7$ versus $3.0 \pm 0.6$ in group 2 $(P=0.01)$ (Table III).

Genotype 1 prevailed in both groups, accounting for $78.2 \%$ of the patients (18/23) in group 1 and $90.4 \%$ of the patients in group $2(19 / 21)$. Genotypes 2 and 3 were present in $4.3 \%$ of the patients in group 1 and no patient from group 2. The HCV viral load was higher in group 1 than in group 2.

Liver biopsies were reviewed in 16 patients from group 1 and in 19 patients from group 2 . We found no differences regarding the necroinflammatory activity, fibrosis stage, and iron overload between the two groups; steatosis was present in $87 \%$ of the patients in group 1 versus $42.9 \%$ in group $2(P=0.01)$ (Table IV).

It was observed that $81.3 \%$ of the patients in group 1 and $63.2 \%$ in group 2 had mild or moderate stages

TABLE I. Demographic Characteristics of 21 Monoinfected HCV Patients and 23 Patients Coinfected with HCV and HTLV-1

\begin{tabular}{|c|c|c|c|c|c|}
\hline \multirow[b]{2}{*}{ Variables } & \multicolumn{2}{|c|}{ Coinfected HCV + HTLV1 } & \multicolumn{2}{|c|}{ Monoinfected HCV } & \multirow[b]{2}{*}{$P$-value } \\
\hline & $\mathrm{N}$ & Mean $\pm \mathrm{SD}$ & $\mathrm{N}$ & Mean $\pm \mathrm{SD}$ & \\
\hline Age (years) & 23 & $48.1 \pm 6.0$ & 21 & $49.3 \pm 9.7$ & 0.63 \\
\hline Weight (kg) & 20 & $67.5 \pm 15.6$ & 16 & $69.5 \pm 12.1$ & 0.69 \\
\hline Height $(\mathrm{cm})$ & 19 & $165.2 \pm 11.0$ & 15 & $163.5 \pm 11.5$ & 0.67 \\
\hline Waist circumference $(\mathrm{cm})$ & 7 & $87.1 \pm 7.6$ & 6 & $95.1 \pm 10.0$ & 0.13 \\
\hline BMI $\left(\mathrm{kg} / \mathrm{m}^{2}\right)$ & 19 & $24.3 \pm 4.7$ & 16 & $26.3 \pm 4.4$ & 0.22 \\
\hline
\end{tabular}

BMI, body mass index; N, number of patients evaluated; SD, standard deviation.

TABLE II. Comparison Between the Clinical Variables of 23 Patients Coinfected with HCV and HTLV-1 and 21 Patients Monoinfected With HCV

\begin{tabular}{|c|c|c|c|}
\hline & Coinfected HCV + HTLV1 & Monoinfected HCV & \\
\hline Variables & $\mathrm{N}(\%)$ & $\mathrm{N}(\%)$ & $\mathrm{X}^{2}$ \\
\hline Vaccinated against hepatitis B (Yes) & $13(59.1)$ & $15(71.4)$ & 0.67 \\
\hline Blood or blood-product transfusion (Yes) & $9(40.9)$ & $7(33.3)$ & 0.61 \\
\hline Tattoo (Yes) & $8(36.4)$ & $2(10.0)$ & 0.07 \\
\hline Piercing (No) & $22(100.0)$ & $19(100.0)$ & - \\
\hline Acupuncture (No) & $22(100.0)$ & $18(100.0)$ & - \\
\hline Inhaled drugs (Yes) & $9(40.9)$ & $4(19.0)$ & 0.19 \\
\hline Sharing of needles (Yes) & $5(22.7)$ & $2(10.5)$ & 0.42 \\
\hline Prior use of glass syringes (Yes) & $17(77.3)$ & $17(85.0)$ & 0.75 \\
\hline Prior use of intravenous vitamins (Yes) & $8(36.4)$ & $12(63.2)$ & 0.49 \\
\hline Sexually transmitted disease (Yes) & $8(36.4)$ & $7(35.0)$ & 0.93 \\
\hline History of surgery (Yes) & $15(68.2)$ & $13(61.9)$ & 0.67 \\
\hline Dialysis (No) & $21(100.0)$ & $21(100.0)$ & - \\
\hline Sharing of razor or toothbrush (No) & $19(86.4)$ & $21(100.0)$ & 0.23 \\
\hline
\end{tabular}

$\mathrm{N}$, number of patients evaluated; $\mathrm{X}^{2}=$ Fisher's exact test. 
TABLE III. Biochemical Characteristics of 21 Patients Monoinfected With HCV and 23 Patients Coinfected With HCV and HTLV-1

\begin{tabular}{|c|c|c|c|c|c|}
\hline \multirow[b]{2}{*}{ Variables } & \multicolumn{2}{|c|}{ Coinfected HCV + HTLV1 } & \multicolumn{2}{|c|}{ Monoinfected HCV } & \multirow[b]{2}{*}{$P$-value } \\
\hline & $\mathrm{N}$ & Mean \pm SD & $\mathrm{N}$ & Mean \pm SD & \\
\hline AST-Aspartate aminotransferase (mg/dl) & 21 & $71.0 \pm 63.0$ & 17 & $62.6 \pm 41.7$ & 0.64 \\
\hline ALT-Alanine aminotransferase (mg/dl) & 21 & $67.5 \pm 92.3$ & 17 & $64.6 \pm 58.8$ & 0.91 \\
\hline GGT-Gamma-transpeptidase (mg/dl) & 20 & $137.8 \pm 145.9$ & 16 & $68.2 \pm 64.9$ & 0.67 \\
\hline Total bilirubin (units) & 21 & $0.8 \pm 0.5$ & 16 & $0.8 \pm 0.4$ & 0.88 \\
\hline Direct bilirubin (units) & 21 & $0.3 \pm 0.2$ & 16 & $0.3 \pm 0.3$ & 0.35 \\
\hline Serum iron (units) & 20 & $120.1 \pm 46.8$ & 11 & $102.2 \pm 33.7$ & 0.27 \\
\hline Total protein (units) & 19 & $7.8 \pm 0.7$ & 16 & $7.1 \pm 0.6$ & $<0.01$ \\
\hline Albumin (units) & 19 & $4.1 \pm 0.4$ & 16 & $4.1 \pm 0.5$ & 0.98 \\
\hline Globulin (units) & 19 & $3.6 \pm 0.7$ & 16 & $3.0 \pm 0.6$ & $<0.01$ \\
\hline Alkaline phosphatase (units) & 19 & $80.2 \pm 23.1$ & 13 & $76.1 \pm 22.8$ & 0.62 \\
\hline Platelets (units) & 19 & $210,052.6 \pm 59,625.2$ & 19 & $185,421.1 \pm 67,559.3$ & 0.24 \\
\hline Prothrombin time (\%) & 6 & $93.0 \pm 14.4$ & 2 & $87.6 \pm 17.5$ & 0.68 \\
\hline Triiodothyronine - T3 (units) & 20 & $146.5 \pm 25.9$ & 11 & $152.3 \pm 34.3$ & 0.60 \\
\hline Free thyroxine - T4 (units) & 21 & $0.9 \pm 0.2$ & 15 & $0.9 \pm 0.1$ & 0.91 \\
\hline TSH-Thyroid-stimulating hormone (units) & 21 & $2.3 \pm 2.0$ & 14 & $1.5 \pm 0.6$ & 0.10 \\
\hline Haptoglobin (units) & 21 & $117.5 \pm 79.4$ & 17 & $88.4 \pm 80.4$ & 0.32 \\
\hline
\end{tabular}

$\mathrm{N}$, number of patients evaluated; SD, standard deviation; $P$-value $=$ Student's T test.

TABLE IV. Comparison of Histological Variables Between 23 Patients Coinfected with HCV and HTLV-1 and 21 Patients Monoinfected With HCV.Table IV Comparison of Histological Variables Between 23 Patients Coinfected With HCV and HTLV-1 and 21 Patients Monoinfected With HCV

\begin{tabular}{lrrr}
\hline & \multicolumn{2}{c}{ Coinfected HCV + HTLV1 } & \multicolumn{2}{c}{ Monoinfected HCV } \\
Variables & $\mathrm{N}(\%)$ & $\mathrm{N}(\%)$ & \multicolumn{1}{c}{$\mathrm{X}^{2}$} \\
\hline Iron overload in liver biopsy (No) & $12(85.7)$ & $13(76.5)$ & 0.66 \\
Steatosis in liver biopsy (No) & $3(13.0)$ & $12(57.1)$ & $<0.01$ \\
Inflammatory activity in the biopsy (Mild/Moderate/Severe) (Yes) & $16(69.6)$ & $18(85.7)$ \\
\hline
\end{tabular}

$\mathrm{X}^{2}=$ Fisher's exact test.

of fibrosis (F1-F2) according to their METAVIR score. More advanced fibrosis stages (F3-F4) were found in $18.8 \%$ of the patients in group 1 and in $36.8 \%$ in group 2. Among these patients, cirrhosis was diagnosed in only one patient from group 1 (4.3\%) and in four patients from group 2 (19\%).

The assessment of non-organ-specific autoantibodies was similar in both groups. In addition, the serum levels of IFN- $\gamma$ in groups 4 and 2 were similar, with a median of $1.02 \mathrm{pg} / \mathrm{ml}$ in group 4 versus $1.42 \mathrm{pg} / \mathrm{ml}$ in group $2(P>0.05)$. In group 3 (HTLV monoinfected), we observed higher levels of IFN- $\gamma$ than in the other groups $(6.22 \mathrm{pg} / \mathrm{ml}) \quad(P<0.001)$. The level of this cytokine in group 2 was $2.85 \mathrm{pg} / \mathrm{ml}$, which was higher than that found in groups 2 and 4 but less than that in group 3 (monoinfected by HTLV-1). The IFN- $\gamma$ levels in groups 1 and 3 were not significantly different $(P>0.05)$.

The patients in group 1 had higher serum levels of IFN- $\gamma$ than those in group $2(P<0.01)$. The comparison of IFN- $\gamma$ levels among the four groups revealed a difference in the immunologic profile $(P<0.0001)$, mainly between groups 1 and $2(P<0.01)$ (Fig. 1).

The median levels of this cytokine were $6.37 \mathrm{pg} / \mathrm{ml}$ in group 1 and $8.71 \mathrm{pg} / \mathrm{ml}$ in group 3 , which were significantly different $(P<0.05)$ but not statistically significant compared to the other groups (Fig. 2).

No differences in the Th2 serum cytokine responses were found between groups 1 and 2 (IL-04, IL-05, and IL-6).

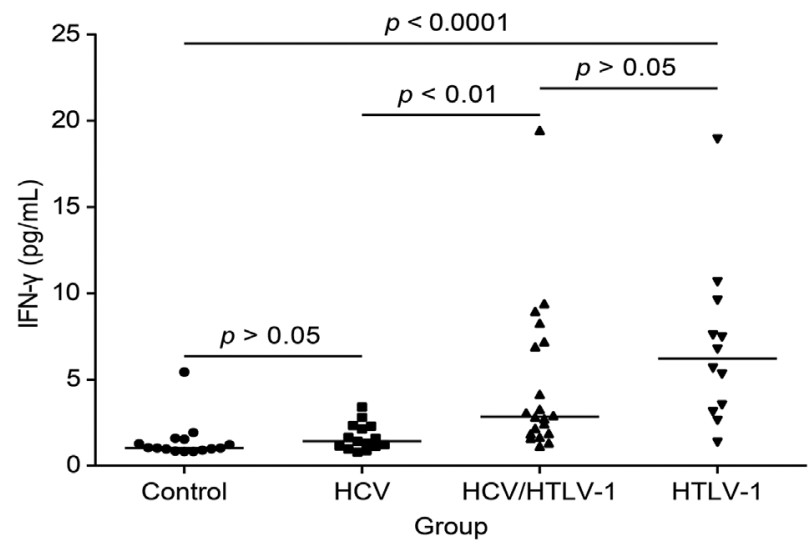

Fig. 1. Serum levels of IFN- $\gamma$ in healthy patients (control), patients chronically monoinfected with HCV (HCV), patients coinfected with HCV and HTLV-1 (HCV/HTLV-1), and patients monoinfected with HTLV-1 (HTLV-1). The medians (control= $1.02 \mathrm{pg} / \mathrm{ml}, \mathrm{HCV}=1.42 \mathrm{pg} / \mathrm{ml}, \mathrm{HCV} / \mathrm{HTLV}-1=2.85 \mathrm{pg} / \mathrm{ml}$, and HTLV-1 $=6.22 \mathrm{pg} / \mathrm{ml}$ ) are represented by horizontal bars. 


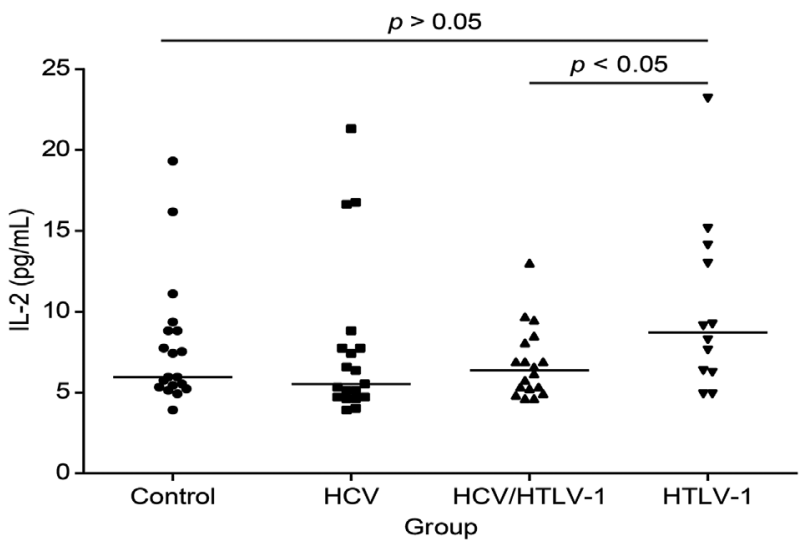

Fig. 2. Serum levels of IL-2 in healthy patients (control), patients chronically monoinfected with HCV (HCV), patients coinfected with HCV and HTLV-1 (HCV/HTLV-1), and patients monoinfected with HTLV-1 (HTLV-1). The medians (control= $5.96 \mathrm{pg} / \mathrm{ml}, \mathrm{HCV}=5.54 \mathrm{pg} / \mathrm{ml}, \mathrm{HCV} / \mathrm{HTLV}-1=6.37 \mathrm{pg} / \mathrm{ml}$, and HTLV $-1=8.71 \mathrm{pg} / \mathrm{ml}$ ) are represented by horizontal bars.

\section{DISCUSSION}

No particular risk factor could be identified for HTLV/HCV coinfected patients in Brazil. The use of intravenous drugs did not seem to be an important risk factor for these parenterally transmitted viruses; however, the use of unsafe injections for licit medicines in the past was likely responsible for most cases of HCV transmission in many parts of the country during the 1970s and 80s [Paraná et al., 1999; Cardoso et al., 2009; Milagres et al., 2009].

Concerning the virological variables, the HCV viral load was similar between both infected groups ( 1 and 2 ), although a slightly higher viral load was observed in the coinfected group $(P>0.05)$. Therefore, the presumed immunologic depression caused by HTLV does not appear to affect HCV replication.

The liver fibrosis stage and necroinflammatory score were similar among groups 1 and 2 . In both groups, we found a predominance of mild to intermediate stage liver fibrosis. Remarkably, steatosis was more frequent in group $1(P<0.05)$ regardless of the anthropometric variables. In these cases of coinfection, the pathogenesis of steatosis is difficult to explain. Clearly, it is not associated with genotype 3 because only a few cases of this genotype were present in both of the HCV-infected groups. Metabolic syndrome does not explain this finding either. It is possible that a putative effect of HTLV on the immunologic cytokine profile could provoke steatosis by an unknown mechanism, but this hypothesis needs to be validated.

It was difficult to compare our immunological analysis with those from other authors because few papers have been published on this topic. Nevertheless, other authors suggest that hepatocyte damage caused by the hepatitis $\mathrm{C}$ virus is known to be triggered by the innate immune and Th1 cell responses. The progression from a milder disease to an advanced liver disease is related to the balance in the serum levels of the Th1 and Th2 responses [Cacciarreli et al., 1996; Poynard et al., 1997; Murata et al., 2002]. HTLV-1 infection reinforces the predominant Th1 response. This mechanism would, therefore, have two functions: (1) to restrict viral replication and (2) to cause more immune-mediated liver damage, but this theoretical mechanism is not supported by our study.

IL-2 is produced by Th1 cells. It induces activated T- and B-cells proliferation, which stimulates cytotoxicity resulting in the death of the infected cell [Carvalho et al., 2001; Porto et al., 2002]. However, we hypothesize that in coinfected individuals, there is a balance in the immunologic profile of the Th1 and Th2 responses that likely decreases hepatocyte injury and, consequently, fibrosis progression.

The B-cell proliferation induced by HTLV could explain the higher globulin level observed in coinfected patients. It has been well documented that HTLV induces polyclonal proliferation [Tygstrup, 1990]. Another study conducted in a Brazilian center found a similar result [Cardoso et al., 2009].

In our study, when the serum IFN- $\gamma$ profile was analyzed, we observed that patients in groups 1 and 3 , both formed by HTLV carriers, had higher levels of this cytokine than patients in groups 2 and 4, who were not infected with HTLV. Therefore, HTLV could be responsible for our findings.

In addition, during the evaluation of the serum levels of IL-2, we observed that patients in group 1 had lower serum levels than those in the other groups (groups 2, 3, and 4). Therefore, the Th1 response induced by HTLV-1 infection seems to be less intense when it is associated with HCV infection. This information reinforces the balance between the Th2 immunological pattern induced by HCV and the Th1 pattern induced by HTLV as a method of modulation of the pathogenesis of HCV.

Other studies that have evaluated specific aspects of HCV/HTLV-1 coinfection have suggested that patients who did not respond to antiviral treatment had a higher probability of developing HCC [Asou et al., 1986; Kishihara et al., 2001]. Therefore, carcinogenesis in HTLV/HCV coinfected patients may be a valid concern.

The poorer response to antiviral treatment and disease accompanied by a milder and more prolonged progression could be related to the development of immunoproliferative disorders in coinfected patients, which has been reported in some studies and reinforces the immunomodulation and immunostimulation role of HTLV [Cacciarreli et al., 1996; Carvalho et al., 2001].

In summary, HCV/HTLV coinfection is an intriguing research field, and studies can reveal more information about the interplay of HCV and the host immune system.

Our study suggests that HCV/HTLV coinfection could result in a slower progression of liver disease. 
Nevertheless, further studies are needed to characterize this putative slow progression of the disease in coinfected patients as well as the higher likelihood of immunoproliferative disease incidence due to proliferative B-cell stimulation. The risk for $\mathrm{HCC}$ and the poorer response to antiviral therapy in $\mathrm{HCV} / \mathrm{HTLV}$ coinfected patients are also concerns that are not clearly defined.

Although this paper was not designed to determine the antiviral treatment response or natural history of HCV/HTLV-I coinfection, our findings do not provide evidence of a more aggressive disease among coinfected patients. Because most of the patients were African-Brazilians, we expected to find more severe disease among this group because this result has been described by other authors [Sterling et al., 2004].

\section{REFERENCES}

Asou N, Kumagai T, Uekihara S, Ishii M, Sato M, Sakai K, Nishimura H, Yamaguchi K, Tatsuki K. 1986. HTLV-I seroprevalence in patients with malignancy. Cancer 58:903-907.

Bittencourt AL. 2006. A importância da transmissão vertical do vírus linfotrópico para células $\mathrm{T}$ humanas tipo I (HTLV-1) no Brasil. Fêmina 34:21-28.

Cacciarreli TV, Martinez OM, Gish RG, Villanueva JC, Krams SM. 1996. Immunoregulatory cytokines in chronic hepatitis $C$ virus infection: pre- and posttreatment with interferon alfa. Hepatology 24:6-9.

Cardoso DF, Souza FV, Fonseca LA, Duarte AJ, Casseb J. 2009. Influence of human T-Cell lymphotropic virus type 1 (HTLV-1) infection on laboratory parameters of patients with chronic hepatitis C virus. Rev Inst Med Trop São Paulo 51:325-329.

Carvalho EM, Bacellar O, Porto AF, Braga S, Galvão-Castro B, Neva F. 2001. Cytokine profile and immunomodulation in asymptomatic human T-lymphotropic vírus type 1-infected blood donors. J Acquir Immune Defic Syndr 27:1-6.

Kishihara Y, Furusyo N, Kashiwagi K, Mitsutake A, Kashiwagi S, Hayashi J. 2001. Human T lympotropic virus type 1 infection influences hepatitis C virus clearance. J Infect Dis 184:11141119 .
Milagres FAP, Duarte MIS, Viso AT, Segurado AC. 2009. Hepatitis $\mathrm{C}$ virus and human T-lymphotropic virus coinfection: Epidemiological, clinical, laboratory and histopathological features. Rev Soc Bras Med Trop 42:363-368.

Murata M, Nabeshima S, Maeda N, Nakashima H, Kashiwagi S, Hayashi J. 2002. Increased frequency of IFN-gamma-producing peripheral CD8 $+\mathrm{T}$ cells with memory-phenotype in patients with chronic hepatitis C. J Med Virol 67:162-170.

Okuda K. 1992. Hepatitis C virus and hepatocellular carcinoma. Adv Appl Biotechnol Series 13:119-119.

Paraná R, Lyra L, Trepo C. 1999. Intravenous vitamin complexes used in sporting activities and transmission of HCV in Brasil Am J Gastroenterol 94:857-858.

Poiesz BJ, Ruscetti FW, Gazdar AF, Bunn PA, Minna JD, Gallo RC. 1980. Detection and isolation of type $\mathrm{C}$ retrovírus particles from fresh and cultured lymphocytes of a patient with cutaneous T-cell lymphoma. Proc Natl Acad Sci USA 77:7415-7419.

Porto MA, André Muniz A, Oliveira Júnior J, Carvalho EM. 2002. Clinical and immunological consequences of the association between HTLV-1 and strongyloidiases. Rev Soc Bras Med Trop 35:641-649.

Poynard T, Bedossa P, Opolon P. 1997. Natural history of liver fibrosis progression in patients with chronic hepatitis C. Lancet 349:825-832.

Poynard T, Yuen MF, Ratziu V, Lai CL. 2003. Viral hepatitis C. Lancet 362:2095-2100.

Seeff LB. 1997. Natural history of hepatitis C. Hepatology 26:21S$28 \mathrm{~S}$.

Sterling RK, Stravitz RT, Luketic VA, Sanyal AJ, Contos MJ, Mills AS, Shiffman ML. 2004. A comparison of the spectrum of chronic hepatitis $\mathrm{C}$ virus between Caucasians and African Americans. Clin Gastroenterol Hepatol 2:469-473.

Stuver SO, Okayama A, Tachibana N, Tsubouchi H, Mueller NE, Tabor E. 1996. HCV infection and liver cancer mortality in a Japanese population with HTLV-1. Int J Cancer 67:35-37.

Sulkowski MS, Mast EE, Seeff LB, Thomas DL. 2000. HCV infection as on opportunistic disease in persons with HCV. Clin Infect Dis 30:77-84.

Tachibana N, Okayama A, Ishizaki J, Yokota T, Shishime E, Murai K, Shioiri S, Tsuda K, Essex M, Mueller N. 1988 Suppression of tuberculin skin reaction in healthy HTLV-1 carriers from Japan. Int J Cancer 42:829-831.

Takatsuki K, Uchiyama T, Sagawa K, Yodoi J. 1977. In: Adult T cell leukemia in Japan, Senoo S, Takaku F, Irino S, editors. Topics in hematology. Amsterdam: Excerpta Medica, pp 73-78.

Tygstrup N. 1990. Assessment of liver function: Principles and practice. J Gastroenterol Hepatol 5:468-482. 